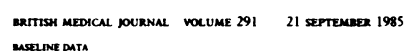

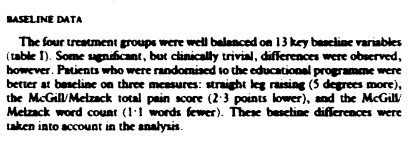

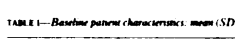

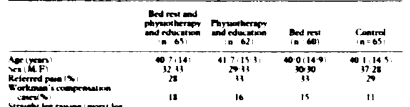

sing

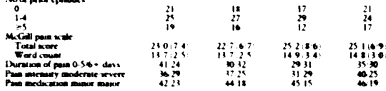

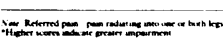

arvice ortrome Hescives

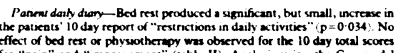

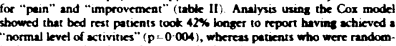

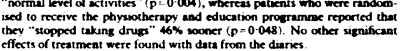

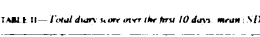

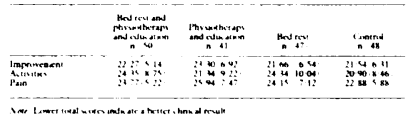

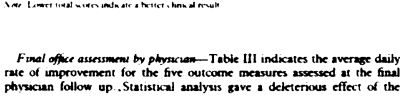

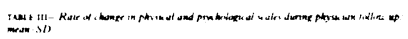

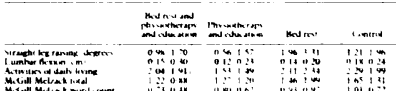

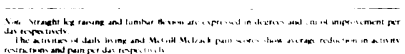
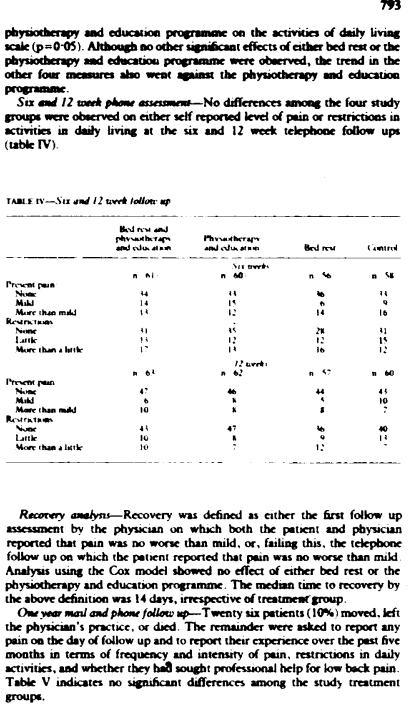

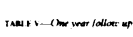

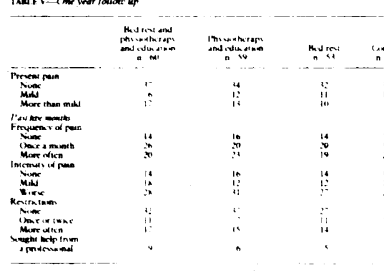

Discescioe

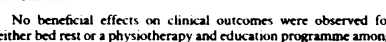

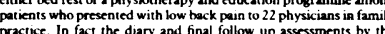

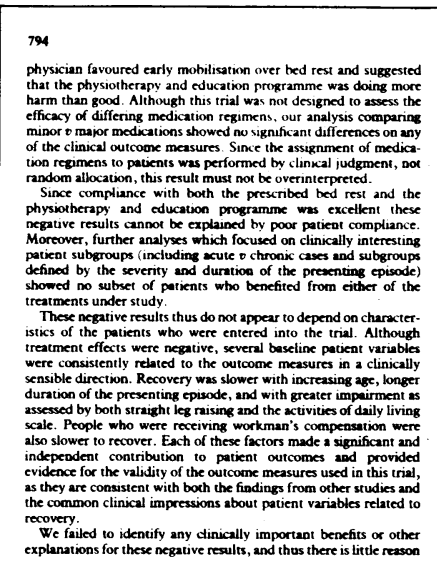

BRRTISH MEDICAL FOLRNAL VOLLIME 291 21 SEPTEMBER 1985 lo prescribe either bed rest or isometric exercises to patients in
family prostice who suffer from low beck pexin.

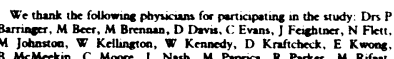

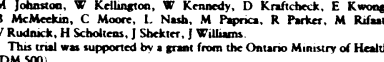

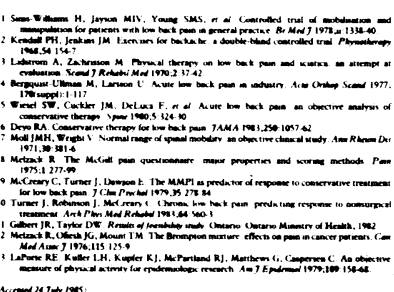

\title{
Survey of health visiting in antenatal care
}

FRANCES MCCABE, YVETTE ROCHERON

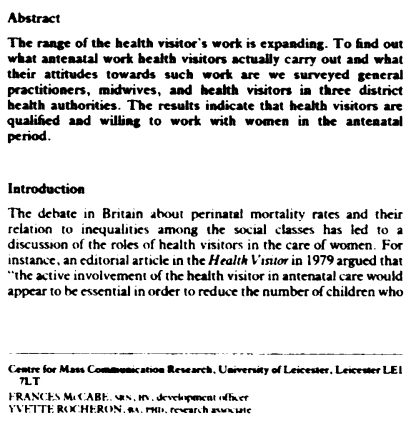

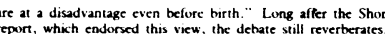

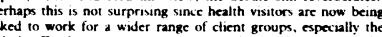

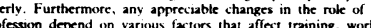

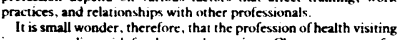

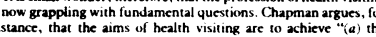

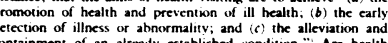

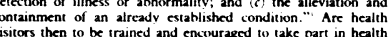

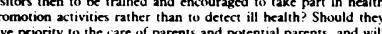
Wve probrity to the care of parents and potchntal parents, and wh

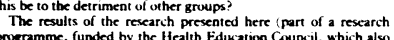

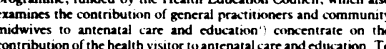

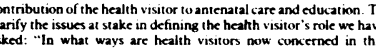

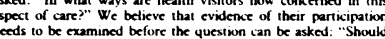

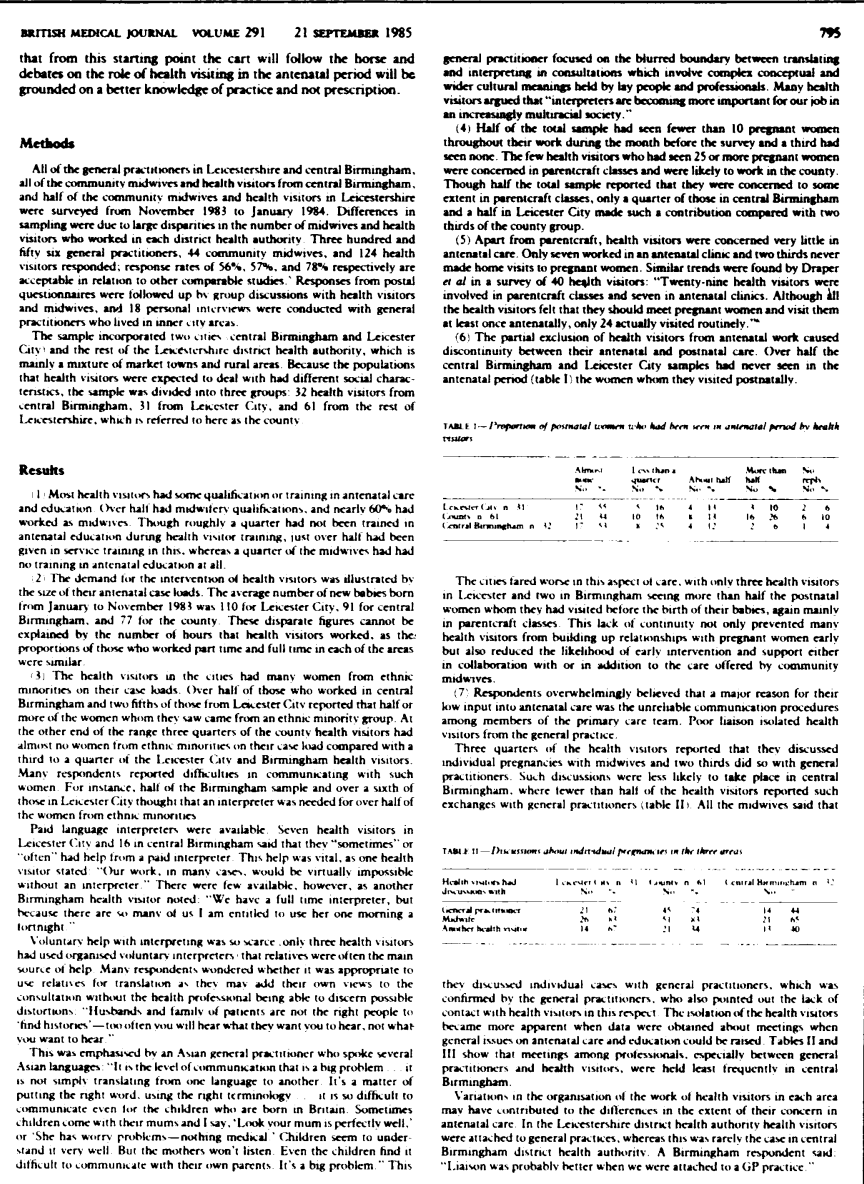

\section{$7 \%$

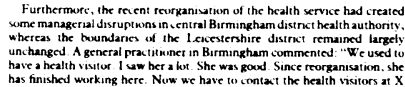

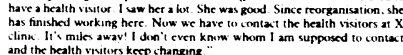

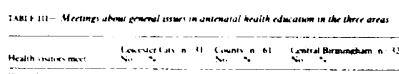

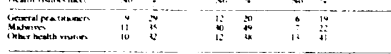

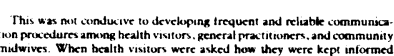

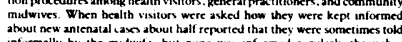

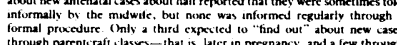

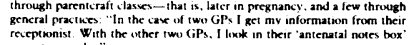

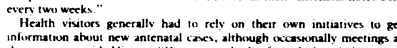

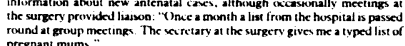

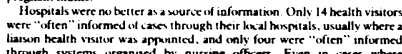

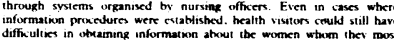

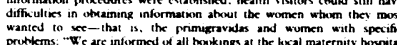

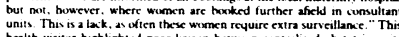

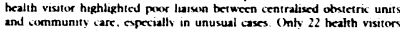

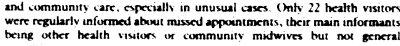

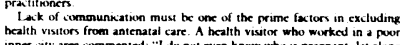

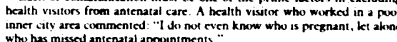

Discuscion

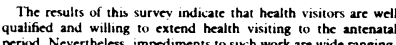
perided, Nevertheless, impediments to such work are wide ranging

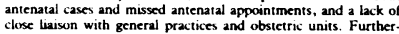

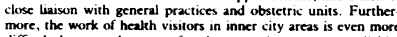

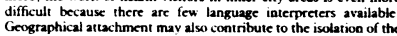

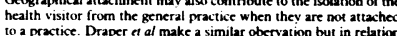

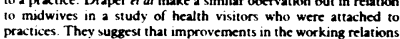

BRTISH MEDTCA JOURNAL VOLLME $291 \quad 21$ SETEMaER 1985

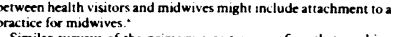

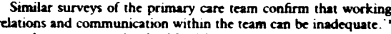

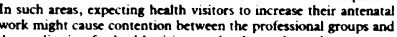

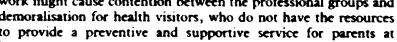
This brings inte quection the value of further abstract recom

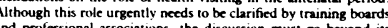

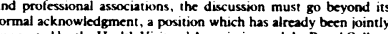

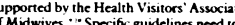

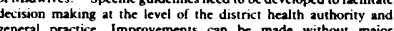

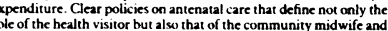

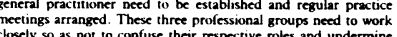
(a)

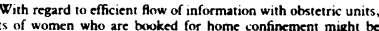

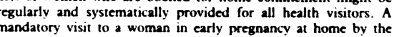
Euth visitor would ensure greater continuity of care between the

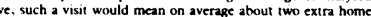

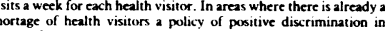
The health visting professions Cerm or long term programmes in antenatal care and cducation

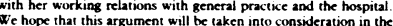

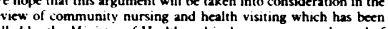
1985. After

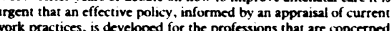

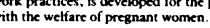

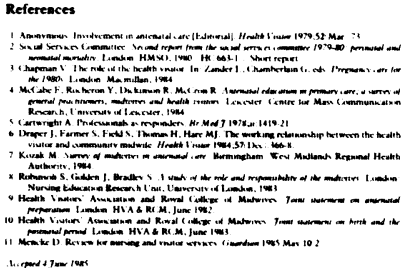

